\title{
LIBROS
}

Protocolo en el Estado de la Ciudad del Vaticano.

Tradición y modernidad.

Análisis histórico, jurídico e institucional de la Santa Sede en relación con su ceremonial y su Protocolo, 3 vols.

Enrique Somavilla Rodríguez, OSA.

2015, Madrid, España, Ed. Religión y Cultura, 1469 págs.

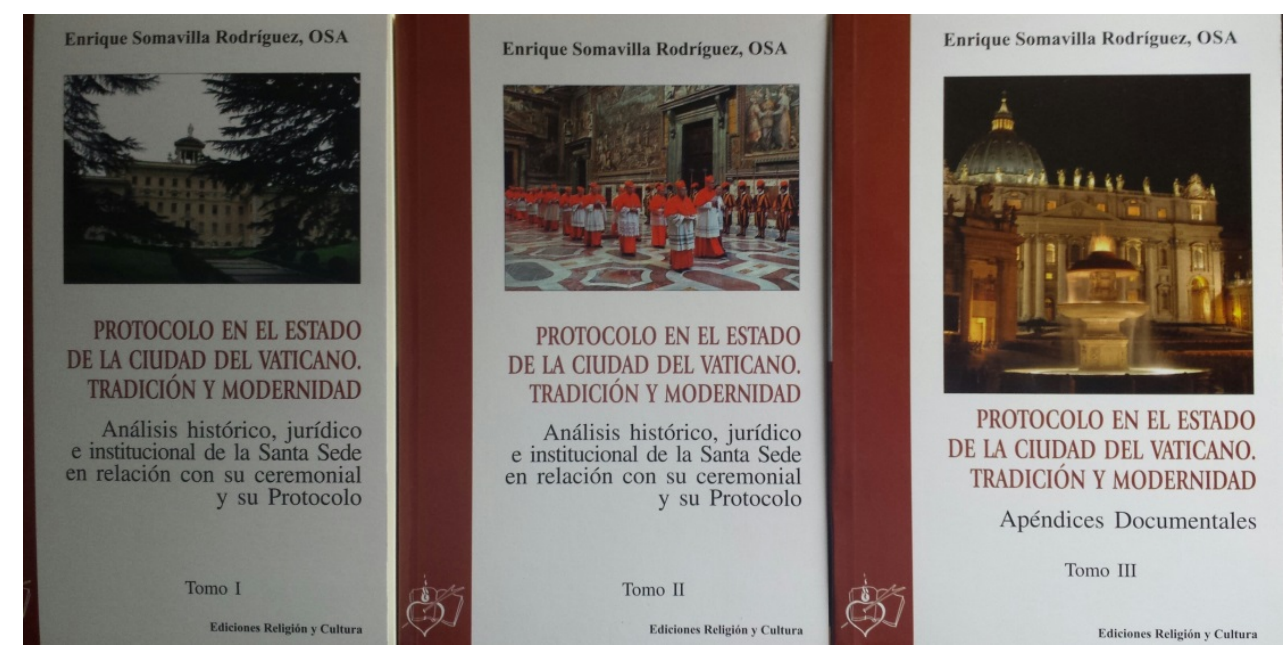

Roberto Noriega1

Centro Teológico San Agustín (Los Negrales), Madrid

Estudio Teológico Agustiniano, Valladolid

rnoriega@agustinos-es.org

Recepción: 12/11/15 Revisión: 15/11/15 Aceptación: 29/11/15 Publicación 01/12/15

\section{Enlace web}

1 Doctor en Teología moral y máster en Bioética, por la Universidad Pontificia Comillas. Profesor ordinario en el CTSA, Centro Teológico San Agustín (Los Negrales) Madrid, afiliado a la Universidad Pontificia de Salamanca y del ETAV, Estudio Teológico Agustiniano de Valladolid, agregado a la Facultad de Teología del Norte (Burgos). 
La presencia pública de la Iglesia en el mundo ha cambiado mucho en los últimos tiempos, de manera particular en el último siglo. El reconocimiento de la Iglesia en los Pactos Lateranenses de 1929, así como la revolución teológico/eclesial que supuso el Concilio Vaticano II en los años 60 se ha ido plasmando en la plaza pública por medio de una serie de actuaciones y protocolos rostro visible de una Iglesia, que trata de ser fiel a la Tradición adaptándola a la modernidad. En los últimos diez años tras la muerte del papa san Juan Pablo II y la renuncia de Benedicto XVI ha adquirido mayor notoriedad si cabe, por la trasmisión en directo de acontecimientos que hasta entonces se desarrollaban en la oscuridad mediática y con una gran dosis de secretismo. El interés generado para conocer la realidad protocolaria y ceremonial vaticana ha favorecido nuevos escritos que iluminen esta realidad en muchos aspectos inédita en la literatura castellana. Dicho interés está en el origen remoto de este libro. Era necesario hacer una presentación comprensible -más allá de las conjeturas y opiniones periodísticas- de toda esa dimensión pública, protocolaria y diplomática. En primer lugar para mayor visión de los cristianos, y para mayor comprensión de los que no lo son, de manera que puedan entender más profundamente el significado civil de una institución milenaria cuya presencia es eminentemente de significado religioso.

Eso es lo que hace Enrique Somavilla en esta obra enfrentando el tema desde una visión histórica, jurídica e institucional, sin renunciar a la dimensión teológica que sin duda enriquece la comprensión, pues el ceremonial eclesiástico tiene un trasfondo teológico que no es posible soslayar salvo grave error de perspectiva. El resultado es una obra valiente por su envergadura y multidisciplinariedad abarcando el periodo de tiempo que va desde la caída de los Estados Pontificios -papado de Pío XI (1846-1878)- hasta Benedicto XVI.

Si se comienza evaluando el apartado metodológico nos encontramos con un texto con un aparato crítico abundante y muy documentado. Es correcto aunque podría haber optado por la citación simplificada. Son tres volúmenes estructurados en dos partes bien definidas. Los dos primeros tomos se corresponden con el cuerpo del texto y el tercero se dedica íntegramente a los apéndices documentales. En los tres volúmenes ha optado por la paginación continuada pero no ha sucedido así con la numeración de los capítulos. La presencia del índice general al final de cada volumen, las siglas y los índices particulares de cada capítulo indican una opción didáctica para los que consulten esta obra. Se verá completada con una abundante bibliografía general al final del segundo volumen y una 'webgrafia' que sostiene una buena parte de esta investigación.

Aunque el autor en el comienzo del trabajo afirma que "Nuestra obra versará sobre el Protocolo en el Estado de la Ciudad de Vaticano" (p. 34) pronto se ve que ese enfoque inicial 
se verá desbordado -y enriquecido- por sus múltiples enlaces y la amplitud de los temas adyacentes, apareciendo otras cuestiones relativas a la Santa Sede -que abordan cuestiones de carácter internacional como las visitas papales, la presentación de credenciales...- y la liturgia de la Iglesia, como Pueblo de Dios. Es una realidad con tres ángulos distintos que formarán un triángulo equilátero como institución con "más de dos milenios de existencia" (p. 38).

El primer volumen (475 pp.) está compuesto por siete capítulos y con buen criterio se inician con el establecimiento y definición de los conceptos. Presenta el protocolo en un sentido amplio como "el conjunto de normas usos sociales y costumbres que determinan cuál es el orden de celebración de un determinado acto o evento, bien público o privado" (p. 49). Y también como "conjunto de conductas y reglas que una persona deberá observar y respetar cuando se mueva en determinados ambientes oficiales, ya sea por cuestiones especiales de la persona o bien porque ostenta algún cargo o responsabilidad que los implica personalmente" (p. 45). O sea, que parte de una concepción del protocolo que habla de la identidad de la persona o de la institución, como modo de comunicación y de transmitir su mensaje lo cual permite comprender las particularidades del protocolo eclesiástico.

Aquí presenta el marco de fondo de la cuestión que es la de la amplitud del protocolo en su relación con el derecho, con el ceremonial y en su dimensión celebrativa con la liturgia. 0 dicho de otro modo la relación de la Iglesia como pueblo de Dios, la Santa Sede como gobierno y sujeto de Derecho Internacional, y la Ciudad del Vaticano como estado independiente, como microestado europeo tras la ratificación de los Pactos Lateranenses en 1929 que resolvieron la denominada Cuestión romana. El autor deja claro cómo los tres entes están separados pero inevitablemente unidos por estrechos lazos, o cómo aunque desapareciera el Estado de la Ciudad del Vaticano la Sede Apostólica seguiría existiendo con personalidad internacional como de hecho lo hizo entre 1870 (desaparición de los Estados Pontificios) y 1929. Solamente realizada esta distinción, será posible estudiar los diversos órganos protocolarios de cada una de dichas instituciones y garantizar la comprensión del trabajo.

Aclarada esa cuestión, avanza con la presentación de las diferentes partes de la Curia Romana como estructura del gobierno de la Santa Sede. Ofrece una primera visualización de la personalidad jurídica de la Santa Sede antes de presentar lo que es la Curia (naturaleza, competencias, organización...), a lo largo de la historia y en la actualidad para mostrar la evolución sufrida en el proceso de adaptación del protocolo eclesial según el desarrollo de los tiempos. Lo aborda en su integridad desde el colegio cardenalicio hasta los otros 
organismos que componen dicha Curia. La Prefectura de la Casa Pontificia "conjunto de personas escogidas para formar parte del entorno del papa en la Santa Sede" (p. 247) merece un capítulo aparte al ser una evolución de la desaparecida corte papal. De este modo, al presentar las funciones y toda la estructura de personal (congregaciones, tribunales, y otras instituciones como son las relativas a la comunicación...) está dando razón de la jerarquía protocolaria que habrá que seguir en las diversas acciones y celebraciones.

Se completa la presentación estructural de la Curia con los aspectos ceremoniales de los dos momentos fundamentales: el proceso de elección del Santo Padre (cap. 5) y el ceremonial de entronización (cap. 6). En efecto, parece que dentro del protocolo interno a la Ciudad del Vaticano lo relativo al cambio de Sumo Pontífice es el momento más importante por los procesos desencadenados desde la muerte del Papa hasta la elección y la entronización del nuevo Santo Padre. No obvia las novedades en los cambios efectuados por los últimos pontífices en una cuestión que envuelve la sensibilidad personal del cabeza de la única monarquía absoluta y electiva del mundo. En la presentación el Dr. Somavilla la dimensión teológica no oscurece la dimensión del poder político-civil, por ejemplo cuando habla del cónclave: "Este proceso que se inicia, no es solo la elección de un papa, sino mucho más. Es una pugna por el poder supremo de la Iglesia, de manera que los allí congregados, en función de las distintas corrientes doctrinales o ideológicas, deben esforzarse por ganar adeptos a su precandidato y establecer las alianzas precisas para que al final éste sea el escogido" (p. 321).

En cuanto al protocolo externo, profundamente relacionado con la diplomacia, también ofrece un recorrido de largo alcance al fundamentarlo en las bases antropológicas sobre las que se sustentan las relaciones humanas, una muestra más del enriquecimiento que ofrece la perspectiva histórica alimentada por la teológica. En ese capítulo séptimo hay que destacar además que el autor se detiene en analizar brevemente la relación de la Sede Apostólica con los Estados de Israel y Estados Unidos por la significatividad y peculiaridad de ambos. Inicia explicando la compleja problemática de la Cuestión romana, necesaria para comprender la solución encontrada a la presencia político-civil (temporal) de una entidad con preocupaciones evangélicas; tras ello se detiene en la delicada situación de Pio XII en relación al pueblo judío y la Alemania nazi apoyándose en la monumental obra de Pierre Blet, Angelo Martin, Robert A. Graham y Burkhart Schneider (pp. 367-377). Igualmente aborda la presentación de las cartas credenciales y las visitas de los jefes de estado al Vaticano, así como las visitas del Santo Padre a otro país, entendiendo que son los momentos más peculiares del ceremonial externo e internacional de la Santa Sede, que reposa sobre el derecho concordatario. En este apartado se presentan asimismo las 
celebraciones de las beatificaciones con los cambios sucedidos en los últimos tiempos.

El segundo volumen (452 pp.) fluye a lo largo de cinco capítulos, que comienzan con la exposición del Estado de la Ciudad del Vaticano que ocupa una gran parte de este tomo (156 pp.). Resulta muy interesante señalar las diversas entidades que lo componen. Como cualquier estado tiene sus límites geográficos, símbolos, legislación y otras muchas instituciones -en las que se destacan los museos- que el autor enumera con suficiencia. Más atractivo conlleva el Derecho premial (cap. II), por el significado de las condecoraciones ofrecidas y por las precedencias que facilitan la organización en las celebraciones. En ellas se muestra igualmente la evolución histórica de la sensibilidad de la Santa Sede acorde el trascurso de los tiempos y de las sociedades.

El análisis histórico vuelve a hacerse presente con fuerza en el capítulo III (138 pp.) que analiza el protocolo de cada Pontificado desde Pío IX hasta la actualidad. Dada la sorpresa que supuso la renuncia de Benedicto XVI, Somavilla se preocupa en señalar los diversos pontificados que de algún modo renunciaron... A continuación presenta la heráldica papal en el mismo período de tiempo señalando uno de los instrumentos que indican el respeto a la tradición y la evolución hacia la modernidad. El escudo papal conlleva elementos familiares, culturales e históricos, encarna la aceptación de responsabilidades y dignidades que hay que tener presentes en el ceremonial y el protocolo. Amén de que "el lema y el escudo que elige cada papa, y de cada obispo también, indican lo que alienta al Pastor e idealmente también lo que desea inculcar en sus fieles" (p. 785). De tono práctico son los breves capítulos IV dedicado a los Tratamientos eclesiásticos- (pp. 791-803), y V - las Precedencias eclesiásticas(pp. 805-821) y su relación con las precedencias civiles ajustado a la realidad española.

Fiel a su discurso en este segundo tomo el autor mantiene las diferencias de protocolo entre las tres entidades: "La Iglesia lleva adelante su protocolo mediante la liturgia correspondiente a los actos religiosos; la Santa Sede los expresa por medio de la acción del papa y de la Curia romana, en su particular minucioso protocolo y el Estado de la Ciudad del Vaticano se expresa como cualquier otro Estado ejerciendo su soberanía temporal y su particular protocolo" (p. 519). Sin olvidar la estrecha unión entre Estado (Ciudad del Vaticano), Gobierno (Santa Sede) y Pueblo de Dios (Iglesia). En sus manifestaciones externas y protocolos de acción están unidos "bajo una misma dimensión interna, que hace posible su vertebración, sentido y fuerza, que les da sentido y coherencia desde el punto de vista del protocolo" (p. 789). Quizás por ello se afirme que es el más refinado y sutil: "Si se reflexiona sobre las imágenes y expresiones en sí mismas, tanto la puesta en escena de sus celebraciones como los ceremoniales y su propia etiqueta, dada da riqueza de los rituales de 
la Iglesia católica, no es en nada comparable con cualquier otra institución o estado" (p. 810). En la teoría esta distinción puede estar clara pero el mismo autor reconoce que el protocolo vaticano no es fácilmente comprensible (p. 788) por cuanto las facultades de los poderes ejecutivo, legislativo y judicial del Soberano Pontífice son delegadas en el Governatorato del Estado de la Ciudad del Vaticano, y en la Santa Sede como gobierno cuyo servicio exterior se encarga directamente a la Secretaría de Estado con sus dos secciones (Asuntos Generales y Relaciones con los estados).

A lo largo del estudio de justifica la segunda parte del título: Tradición y modernidad. Mostrando gracias al análisis histórico-teológico la evolución sucedida en los múltiples temas tratados. Desde la visión general del protocolo: “El protocolo también debe tener en cuenta que ha de adaptarse poco a poco, y de manera sistemática, al desarrollo de aquellos elementos que sirvan mejor a su propio cometido, con flexibilidad, apertura, modernidad, adaptación y plena vigencia que deben estar unidos a las tradiciones más genuinas, representativas y ejemplares para el mejor funcionamiento en el comportamiento social de las personas y también de las instituciones" (p. 786) hasta situaciones más concretas como la coronación y entronización que ha sido sustituida por la actual ceremonia de inicio del "ministerio petrino" en consonancia con la actual comprensión de la misión del papado.

El tercer y último volumen (542 pp.) está compuesto por los apéndices documentales. De ese modo respalda las afirmaciones anteriores con una selección de documentos acertada por haber escogido los más significativos e importantes en los temas tratados. Son de diverso calado desde las leyes fundamentales y acuerdos internacionales que dan entidad internacional a la Santa Sede frente al Estado italiano, leyes de organización interna del Estado de la Ciudad del Vaticano, la organización de la Curia, los documentos magisteriales que ordenan la elección del Santo Padre en el cónclave, así como listas de personas (nuncios, embajadores, cardenales camarlengos) y acontecimientos (consistorios) y discursos papales, heráldica papal e indumentaria litúrgica; hay un apéndice fotográfico de las tiaras y sillas gestatorias. Se acuerda de la realidad española presentando un elenco de nuncios. Otros son discursos a la Academia Pontificia Eclesiástica (Escuela de diplomática de la Santa Sede/Vaticano).

En los temas que podría haber mejorado se echa en falta la presentación más extensa de los distintos tipos de documentos utilizados en diplomacia; igualmente parece que podría haber sido importante el análisis de la realidad de la Santa Sede junto a la Organización de las Naciones Unidas como estado observador, del mismo modo que se ha insistido en la relación con Israel o EEUU. Por otro lado, sin duda que el protocolo eclesiástico ha sido influido y ha 
Influido -y mucho- en el protocolo actual; esa es una realidad insinuada en pequeños momentos pero no trabajada con mayor profundidad. Parece que hubiera sido conveniente explicar el origen evangélico de la estructura jerárquica eclesial para comprender mejor la función principal evangelizadora que necesita de un soporte temporal que ha evolucionado a lo largo de los siglos llegando a una monarquía absoluta y electiva.

Se encuentran algunas repeticiones en textos cercanos como "La Iglesia católica es la única institución religiosa que puede establecer relaciones diplomáticas oficiales con otros países miembros soberanos de la comunidad internacional" (pp. 63 y 66-67), las entidades internacionales en las que tiene participación el Estado Ciudad del Vaticano (pp. 524 y 528) o la referencia a la monumental obra que recoge los documentos de la Santa Sede en relación a la Segunda Guerra Mundial y la posición tomada por Pio XII (pp. 376 y 704-705). Algunas pequeñas discordancias permitidas en una obra de este calado; por ejemplo en la lista de tiaras que se conservan algunas de las cuales aparecen en el apéndice documental habla de quince (pp. 355-356) y un poco más adelante se señala que aún se conservan "más de 20 tiaras" (p. 358).

En la evaluación final hay que decir que es un trabajo importante por varias razones. Ayuda a distinguir lo que es la Santa Sede, el Estado de la Ciudad del Vaticano y la Iglesia universal, paso fundamental para comprender muchas de las decisiones posteriores, la toma de posiciones frente a las tres realidades, la comprensión de lo documentos emanados,... En un mundo que frecuentemente confunde los concordatos entre dos Estados soberanos con acuerdos de tono piadoso, entre una realidad religiosa y otra estatal este es un paso fundamental para aclarar ideas y poder plantear adecuadamente los problemas que se presentan y buscar las soluciones.

Presenta resumidamente y en clave histórica la estructura y organismos que componen la Santa Sede y el Estado Ciudad del Vaticano. Estructuras a nivel externo e interno, así como algunas cuestiones de singular importancia como las ya aludidas relaciones con EE.UU. e Israel, los procedimientos en la declaración de la Sede vacante y entronización del Santo Padre y las celebraciones de las beatificaciones...

Es importante también señalar la evolución histórica de los organismos y las instituciones vaticanas para comprender el proceso de adaptación realizado por la Sede Apostólica a los nuevos tiempos. La perspectiva adoptada en esta obra facilita esa lectura mostrando la dependencia de los acontecimientos que han influido en la evolución del protocolo y el ceremonial de la Santa Sede (la caída de los Estados Pontificios o las dos Guerras Mundiales). Las realidades no aparecen por generación espontánea y la noticia histórica ofrece una rica 
perspectiva de comprensión de sus causas. Así pues se comprende la siguiente afirmación: "El protocolo establecido ha ido evolucionando con los tiempos y se ha ido adaptando a los diversos servicios con el mismo personal que ya existía: simplemente han variado sus funciones $u$ oficios pero han permanecido los emblemas de las personas asignadas" (p. 261). Aunque las denominaciones eclesiásticas tengan un cierto resabio medieval (más cuando se nombran en latín) sin embargo representan funciones diplomáticas y protocolarias de contenido actual.

Expone el valor real del 'poder' papal como algo de tono pastoral, evangélico, conjugándolo con la realidad temporal necesaria para tener una visibilidad en el mundo en que nos encontramos. Además destaca la importancia de la jerarquía en la prosperidad de la Iglesia: "Ninguna otra institución de poder, ya sea espiritual o terrenal, ha perdurado tanto en el tiempo como la Iglesia católica y parte de su secreto ha constituido en no quebrar nunca su estructura jerárquica" (p. 285). Ésta se ha apoyado en estructuras paralelas para desarrollar funciones específicas pero no ha lesionado la estructura inamovible de su jerarquía. O sea, queda clara la importancia del protocolo y la diplomacia vaticana para alcanzar los valores evangélicos (su objetivo). Entre ellos destaca la paz -en medio de dos guerras mundialesbuscada por medio de documentos, el establecimiento de relaciones internacionales con la apertura de nunciaturas, ofertas de diálogo e intermediación, la neutralidad... Este objetivo evangélico se ha plasmado en el protocolo vaticano llevando a la Santa Sede y al Estado Ciudad del Vaticano a buscar la libertad y la independencia en sus acciones.

Es un trabajo de investigación desde el derecho civil a partir del estudio del protocolo como disciplina autónoma. En ese sentido sitúa adecuadamente el protocolo como ciencia que va adquiriendo la importancia que le corresponde. Es un campo poco explorado y en esta obra se aborda adecuadamente la relación del protocolo con la diplomacia, cuya importancia radica en ser garante de comunicación y el éxito de dicha tarea en los más altos niveles. El protocolo diplomático es "el vehículo para establecer una mayor fluidez en las recepciones diplomáticas y conseguir mayores posibilidades de éxito con respecto a las negociaciones de tipo internacional y para un mayor diálogo entre los agentes diplomáticos" (p. 390 citando a Martínez Morcillo). Señala igualmente que la ambigüedad y la incertidumbre son enemigas de la comunicación diplomática que usa de la retórica y de otros medios para conseguir sus fines de una buena comunicación respetando las reglas ya establecidas. Aplicar estos criterios contemporáneos al protocolo y a la diplomacia de la Santa Sede es el gran acierto de fondo de este estudio que advierte de la importancia de la diplomacia y el derecho concordatario, y la educación diplomática en las escuelas propias para ello como la Pontificia Academia Eclesiástica. 
Es un trabajo interdisciplinar de gran valor al armonizar bien todas las dimensiones que conjuga histórica, teológica, jurídico/protocolar, diplomática que inevitablemente provocan la ampliación del texto. Al mismo tiempo recopila y organiza materiales que de otro modo habría necesidad de buscar -no siempre fáciles de encontrar- en el amplio mundo de lo virtual. No se le escapan detalles desde los más simples (como los colores litúrgicos necesarios para cualquier persona profana del tema) hasta aproximaciones más complejas como el desarrollo de las celebraciones vaticanas (los viajes del Santo Padre o la presentación de las credenciales por parte de los nuevos embajadores que no pueden ser los mismos embajadores de la República de Italia). Esa mezcla entre la teoría y las consideraciones prácticas de los ceremoniales lo hacen útil para identificar enseñas, preferencias, condecoraciones, celebraciones,... tanto en el aspecto político-civil como en el campo más litúrgico-celebrativo. En ese sentido es un compendio muy válido para aquellas personas que tengan que cubrir noticias y organizar acontecimientos religiosos -clérigos incluidos-. El mismo autor señala las deficiencias informativas a este respecto (p. 811, nota 8, y 812). Puede servir de manual para aquellos interesados en conocer el sentido, la razón de ser y la evolución del protocolo eclesial, incluso en muchos de sus aspectos prácticos.

El Dr. Somavilla, ya nos anticipaba en la introducción general (pp. 38-39) cuando expresaba: "La palabra, la música, la entonación, la fuerza, la energía, la hondura del corazón que busca y quiere encontrar el sentido religioso y espiritual de cada hombre. La consistencia arrebatadora que nos mueve a buscar el porqué de las cosas, el sentido que poseen, los medios que tenemos a nuestro alcance, la necesidad de utilizarlos, los objetivos propuestos y los fines perseguidos. Todo ello nos lo ofrece el protocolo en general.

Pero sin duda, el protocolo en la Ciudad del Vaticano, como Estado nos va a conseguir, mayores expresiones de su actuación en los ámbitos internacionales; nos orientará a la milenaria tradición de la existencia de la Sede Apostólica, que nos ayudará a comprender mejor su protocolo como Gobierno; y por último la liturgia de la Iglesia como Pueblo de Dios que con su protocolo nos proporcionará, elevadas cuotas de la Sabiduría de Dios. Todo ello se unifica en una única expresión de saber estar. El protocolo de las tres entidades". Sin duda, lo ha conseguido, en una obra monumental.

Roberto Noriega

This work is licensed under a Creative Commons Attribution 3.0 Unported License 